\title{
Fibromyalgia as a Contextual Factor Influencing Disease Activity Measurements in Spondyloarthritis and Psoriatic Arthritis
}
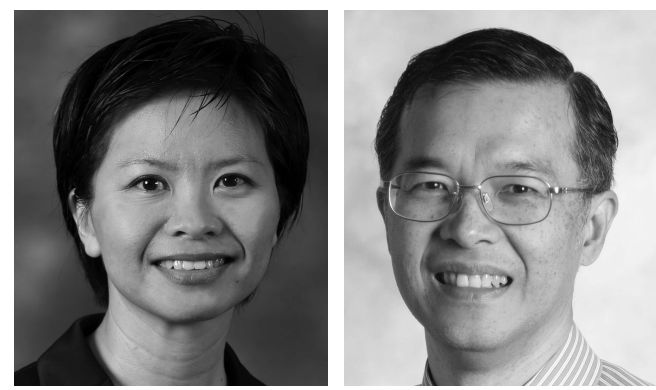

Psoriatic arthritis (PsA) and spondyloarthritis ( $\mathrm{SpA}$ ) are chronic inflammatory conditions that cause progressive joint damage and disability. Apart from causing swelling and pain in multiple joints and entheseal sites, they are associated with fatigue, emotional effects, and poor health-related quality of life (HRQOL). Fibromyalgia (FM) is a chronic condition probably related to variations in central pain processing ${ }^{1}$ and is characterized by widespread bodily pain associated with somatic symptoms including fatigue and sleep disturbance. These manifestations of FM may overlap with those of PsA and SpA. It is also well known that FM may coexist with various rheumatic diseases. For example, the prevalence of FM among patients with rheumatoid arthritis (RA), systemic lupus erythematosus, and Sjögren syndrome was higher than that expected in the general population ${ }^{2}$.

In this issue of The Journal, Wach, et $a l^{3}$ and in a recent issue, Brikman, et $a l^{4}$, described the coexistence of FM in $17.8 \%$ of PsA and $17.5 \%$ of SpA patients, respectively. Women had a higher prevalence of concomitant FM in both conditions. Patients who had concomitant FM-PsA or FM-SpA in these studies had worse disease activity scores. Wach, et al also demonstrated that outcome measures [Ankylosing Spondylitis Disease Activity Score-C-reactive protein (ASDAS-CRP)] that incorporated objective measurement of systemic inflammation (CRP) were less influenced by concomitant FM. Symptoms of FM-like bodily pain and fatigue can mimic disease activity, while objective biomarkers of inflammation are less likely to be falsely positive and may thus reflect disease activity more accurately.

These findings were consistent with another study in axial PsA and ankylosing spondylitis, which reported that the version of ASDAS that incorporated both CRP and erythrocyte sedimentation rate (ESR) was superior in distinguishing the overall health status to the purely patient-reported Bath Ankylosing Spondylitis Disease Activity Index ${ }^{5}$. These reports highlight the need for awareness of the effects of concomitant FM in patients with PsA or SpA, and show that caution is needed in interpreting disease activity assessments (especially when based purely on patient reports) in such patients.

Assessment of disease activity is critical for optimizing treatment outcomes for patients with inflammatory arthritis, including PsA and SpA. The use of patient-reported outcomes has become core to rheumatology, as has their incorporation into the assessment of disease activity and as responder criteria. From the experience with patients with RA, there have been reports of concomitant FM (FM-RA) overestimating objective RA severity measured by composite 28-joint Disease Activity Scores (DAS28) ${ }^{6,7}$. The higher DAS28 scores in FM-RA were driven by patient global assessment and tender joint count, but not by swollen joint count and ESR. Interestingly, patients with FM-RA had lower radiographic damage than patients without FM-RA ${ }^{6}$, suggesting that FM can lead to increased levels of patient-assessed components of disease activity scores without influencing longterm joint damage. Because pain, patient global assessment, fatigue, and tender joint counts are commonly used for the assessment of disease activity in PsA and SpA, disease activity may also be overestimated among patients with FM-PsA and FM-SpA.

Following the advocacy of the Outcome Measures in Rheumatology (OMERACT) to standardize a core domain set for a given rheumatic disease before considering instruments to select to measure outcomes ${ }^{8}$, the Group for Research and Assessment of Psoriasis and Psoriatic Arthritis (GRAPPA) has separated both skin and joint disease activity as a different core concept (domain) as compared to other domains such as fatigue and HRQOL in the updated core outcome set for $\mathrm{PsA}^{9}$. This represents a needed and

See Effect of FM on SpA, page 2056; and Effect of FM on PsA, page 1749, September 2016 issue

Personal non-commercial use only. The Journal of Rheumatology Copyright (C) 2016. All rights reserved. 
important move toward more objective measurement of disease activity as distinct from other domains, which serve different purposes in clinical trials and daily practice. Although the perfect instruments that represent joint or skin activity have yet to be validated or endorsed, there is potential that one of the composite indices, such as the Composite Psoriatic Disease Activity Index, or the Disease Activity Index for Psoriatic Arthritis, which combines active joint count and CRP, could fulfill the OMERACT filter of "truth" for the measurement of disease activity.

For SpA, where assessment of disease activity using physical signs is not possible, and where routine imaging for assessment is not feasible, assessing disease activity using patient-reported outcomes remains a common practice. This may lead to inappropriately high disease activity scores in patients with FM-SpA. Incorporating objective measures such as CRP in the ASDAS could partially improve the performance of the instrument. However, only $40 \%$ to $60 \%$ of patients with axial SpA may have an elevated CRP. Emerging biomarkers such as high-sensitivity C-reactive protein may represent disease activity more accurately in patients with $\mathrm{SpA}^{10}$. A panel of biomarkers may also hold promise: for example, in RA, a panel of 12 biomarker proteins in serum was shown to be more sensitive than CRP alone in reflecting disease activity in RA patients with and without $\mathrm{FM}^{11}$. Other measures such as the synovitis scores and power Doppler signals on ultrasound were not affected by FM in patients with RA, which may help distinguish inflammatory arthritis disease activity from $\mathrm{FM}^{12}$. Ultrasound was capable of distinguishing $\mathrm{SpA}$ versus mechanical-related enthesitis ${ }^{13}$; however, its role in distinguishing enthesitis in SpA from FM is unclear.

There has been increasing recognition of the need to consider the effect of contextual factors (CF) in outcome measurement. There are currently 2 main definitions of $\mathrm{CF}$. The International Classification of Functioning, Disability and Health of the World Health Organization defines CF as variables belonging to the background of the patient (personal factors) or environment (environmental factors) that can influence the functioning and disability of the individual ${ }^{14}$. More emphasis has been given to environmental factors. OMERACT defines a $\mathrm{CF}$ as a "variable that is not an outcome of the study, but needs to be recognized (and measured) to understand the study results"15. Under OMERACT, the concept of CF is strictly defined and is different from the "context" as used to define "setting" of a clinical trial ${ }^{15}$. Comorbidities, differences in healthcare systems, and psychological status are all potential CF. The concept of $\mathrm{CF}$ is relatively new in the field of rheumatology and OMERACT, and which CF should be considered as "core" or "important" for the domain set of different disease entities has yet to be defined, let alone measured ${ }^{8}$. This may lead to confusion as to which factors should be labeled core domains versus CF. An example of possible confusion is emotional well-being, which could be a direct or indirect effect of PsA. Patients have consistently rated emotional well-being as an important core domain in PsA. Confusion can arise because the end of the spectrum of emotional well-being, depression, could also be a CF in the assessment of PsA disease activity. For instance, depression may increase the perception and reporting of pain level, patient global assessment, and even the number of tender joints, which are typical components of disease activity.

Given the contrasting patho-etiologies between FM and inflammatory arthritis, FM can be a CF in measurement of disease activity in chronic inflammatory arthritis. However, the pathology of FM is increasingly described as a disorder of central sensitization. Over the last decade, there has been a shift away from defining FM as a trigger point disorder and towards a definition as a syndrome of widespread pain and its associated psychological and somatic effects. Multiple-site chronic pain is now thought of as a continuum of experience, rather than a discrete disorder ${ }^{16}$. Central sensitization has also been described as a continuum of experience in various chronic arthritis conditions, including osteoarthritis $(\mathrm{OA})^{17}$ and RA ${ }^{18}$. Patients with these chronic forms of arthritis had a lower pressure pain threshold (a surrogate of central sensitization) as compared to healthy controls, and the pain threshold may improve after effective treatment, such as arthroplasty in $\mathrm{OA}^{19}$. The extent to which FM affects disease activity and to which chronic pain from joint inflammation induces central sensitization remains enigmatic.

In short, the coexistence of FM with PsA and SpA is recognized and can confound the objective assessments of disease activity of PsA and SpA. Thankfully, there are newer biomarkers (biochemical or imaging) that may better reflect the "truth" aspect of disease activity to guide in both clinical practice and trial settings. While the new OMERACT framework is helping to improve understanding of the importance of $\mathrm{CF}$, the question of whether $\mathrm{CF}$ such as FM interact with disease activity and longterm outcomes remains unanswered. Evidence with patients with RA has shown that FM not only influences the assessment of disease activity, but also continues to worsen disability outcomes in inflammatory arthritis over a 5-year followup period $^{20}$. On the other hand, chronic pain from PsA and SpA can induce central sensitization and in turn lead to FM. Further research on the neurophysiologic mechanisms of chronic pain in different types of inflammatory arthritis will elucidate the possible pathological link between these conditions.

\section{ACKNOWLEDGMENT}

We thank Serene Ong, Academic Medicine Research Institute, Duke-NUS Medical School, for her help in manuscript preparation.

Personal non-commercial use only. The Journal of Rheumatology Copyright @ 2016. All rights reserved. 
YING YING LEUNG, MD,

Department of Rheumatology and Immunology, Singapore General Hospital; and Duke NUS Medical School, Singapore;

JULIAN THUMBOO, MD, Department of Rheumatology and Immunology, Singapore General Hospital; Duke NUS Medical School; and Department of Medicine, Faculty of Medicine, National University of Singapore, Singapore.

Address correspondence to Dr. Y.Y. Leung, Department of Rheumatology and Immunology, Singapore General Hospital, The Academia, level 4, 20 College Road, Singapore 169856. E-mail: katyccc@hotmail.com

\section{REFERENCES}

1. Bellato E, Marini E, Castoldi F, Barbasetti N, Mattei L, Bonasia DE, et al. Fibromyalgia syndrome: etiology, pathogenesis, diagnosis, and treatment. Pain Res Treat 2012;2012:426130.

2. Gran JT. The epidemiology of chronic generalized musculoskeletal pain. Best Pract Res Clin Rheumatol 2003;17:547-61.

3. Wach J, Letroublon MC, Coury F, Tebib JG. Fibromyalgia in spondyloarthritis: effect on disease activity assessment in clinical practice. J Rheumatol 2016;43:2056-63.

4. Brikman S, Furer V, Wollman J, Borok S, Matz H, Polachek A, et al. The effect of the presence of fibromyalgia on common clinical disease activity indices in patients with psoriatic arthritis: a cross-sectional study. J Rheumatol 2016;43:1749-54.

5. Salaffi F, De Angelis R, Carotti M, Gutierrez M, Sarzi-Puttini P, Atzeni F. Fibromyalgia in patients with axial spondyloarthritis: epidemiological profile and effect on measures of disease activity. Rheumatol Int 2014;34:1103-10.

6. Coury F, Rossat A, Tebib A, Letroublon MC, Gagnard A, Fantino B, et al. Rheumatoid arthritis and fibromyalgia: a frequent unrelated association complicating disease management. J Rheumatol 2009;36:58-62.

7. Pollard LC, Kingsley GH, Choy EH, Scott DL. Fibromyalgic rheumatoid arthritis and disease assessment. Rheumatology 2010;49:924-8.

8. Kirwan JR, Boers M, Hewlett S, Beaton D, Bingham CO, 3rd, Choy $\mathrm{E}$, et al. Updating the OMERACT filter: core areas as a basis for defining core outcome sets. J Rheumatol 2014;41:994-9.

9. Orbai AM, de Wit M, Mease P, Shea J, Gossec L, Leung YY, et al. International patient and physician consensus on a psoriatic arthritis core outcome set for clinical trials. Ann Rheum Dis 2016 Sep 9 (E-pub ahead of print).
10. Poddubnyy DA, Rudwaleit M, Listing J, Braun J, Sieper J. Comparison of a high sensitivity and standard $\mathrm{C}$ reactive protein measurement in patients with ankylosing spondylitis and non-radiographic axial spondyloarthritis. Ann Rheum Dis 2010; 69:1338-41.

11. Lee YC, Hackett J, Frits M, Iannaccone CK, Shadick NA, Weinblatt ME, et al. Multibiomarker disease activity score and C-reactive protein in a cross-sectional observational study of patients with rheumatoid arthritis with and without concomitant fibromyalgia. Rheumatology 2016;55:640-8

12. da Silva Chakr RM, Brenol JC, Behar M, Mendonca JA, Kohem $\mathrm{CL}$, Monticielo OA, et al. Is ultrasound a better target than clinical disease activity scores in rheumatoid arthritis with fibromyalgia? A case-control study. PLoS One 2015;10:e0118620.

13. Milutinovic S, Radunovic G, Veljkovic K, Zlatanovic M, Zlatkovic Svenda M, Perovic Radak M, et al. Development of ultrasound enthesitis score to identify patients with enthesitis having spondyloarthritis: prospective, double-blinded, controlled study. Clin Exp Rheumatol 2015;33:812-7.

14. World Health Organization. How to use the ICF: A practical manual for using the International Classification of Functioning, Disability and Health (ICF). Exposure draft for comment. Geneva: WHO; October 2013. [Internet. Accessed September 20, 2016]. Available from: www.who.int/classifications/drafticfpracticalmanual2.pdf?ua $=1$

15. Boers M, Kirwan JR, Tugwell P, Beaton D, Bingham II CO, Conaghan PG, et al. The OMERACT Handbook. 2015. [Internet. Accessed September 20, 2016]. Available from: www.omeract.org/pdf/OMERACT_Handbook.pdf

16. Wolfe F, Michaud K. Outcome and predictor relationships in fibromyalgia and rheumatoid arthritis: evidence concerning the continuum versus discrete disorder hypothesis. J Rheumatol 2009;36:831-6.

17. Lluch E, Torres R, Nijs J, Van Oosterwijck J. Evidence for central sensitization in patients with osteoarthritis pain: a systematic literature review. Eur J Pain 2014;18:1367-75.

18. Meeus M, Vervisch S, De Clerck LS, Moorkens G, Hans G, Nijs J. Central sensitization in patients with rheumatoid arthritis: a systematic literature review. Semin Arthritis Rheum 2012; 41:556-67.

19. Kosek E, Ordeberg G. Abnormalities of somatosensory perception in patients with painful osteoarthritis normalize following successful treatment. Eur J Pain 2000;4:229-38.

20. Andersson ML, Svensson B, Bergman S. Chronic widespread pain in patients with rheumatoid arthritis and the relation between pain and disease activity measures over the first 5 years. J Rheumatol 2013;40:1977-85.

J Rheumatol 2016;43:1953-5; doi:10.3899/jrheum.161156

Personal non-commercial use only. The Journal of Rheumatology Copyright (C) 2016. All rights reserved. 